\title{
SOLITARY FIBROUS TUMOR OF THE PLEURA: CASE REPORT AND LITERATURE REVIEW
}

\author{
Marilena Stoian ${ }^{1 \cdot 2}$, Lucia Indrei ${ }^{1}$, Roxana Stănică², Victor Stoica ${ }^{1.2}$ \\ 1"Carol Davila" University of Medicine and Pharmacy, Bucharest \\ 2"Internal Medicine Department," Dr. Ion Cantacuzino" Clinical Hospital, Bucharest \\ Corresponding athor: \\ Marilena Stoian \\ 65 Matei Basarab Street, District 3, Bucharest, Romania \\ E-mail: marilenastoian@yahoo.com
}

\begin{abstract}
Solitary fibrous tumours of the pleura (SFTPS) are rare neoplasms, usually described as relatively benign neoplasms and only 10-20\% presenting malignant features. Imagistic investigations are useful in the incipient evaluation of SFTPS, and the histopathological and immunohistochemical examinations after surgical resection are mandatory for establishing the diagnosis and for differentiating SFTPs from other aetiologies of pleural masses. The unpredictable evolution (10\%-20\% of the cases reported in literature display malignant features) and limited data regarding the treatment needs an early detection, a complete surgical resection and long-term imagistic follow-up. We present a case of SFTPs alongside a review of the typical clinical, imagistic and pathologic features consistent with this diagnosis.
\end{abstract}

Keywords: solitary fibrous tumours of the pleura (SFTPS), immunohistochemical characteristics, paraneoplastic syndromes.

\section{Abstract}

Tumorile fibroase solitare ale pleurei (SFTP) sunt neoplasme rare, de obicei descrise ca relativ benigne, doar 10-20\% prezentând trăsături maligne. Investigațiile imagistice sunt utile în evaluarea inițială a SFTP-urilor, iar examinările histopatologice și imunohistochimice după rezecția chirurgicală sunt obligatorii pentru stabilirea diagnosticului și pentru diferențierea SFTP-urilor de alte etiologii ale maselor pleurale. Evoluția imprevizibilă (10-20\% dintre cazurile raportate în literatură prezintă caracteristici maligne) și datele limitate cu privire la tratament impun detectarea precoce, rezecția chirurgicală completă și urmărirea imagistică pe termen lung. Prezentăm un caz de SFTP alături de o revizuire a caracteristicilor clinice, imagistice și patologice tipice.

Cuvinte cheie: tumori fibroase solitare ale pleurei (SFTP), caracteristici imunohistochimice, sindroame paraneoplazice. 


\section{INTERNAL}

\section{Clinical Cases}

\section{Introduction}

Solitary fibrous tumours (SFTs) are fibroblastic mesenchymal tumours displaying a branching vascular pattern, responsible for the now obsolete term hemangiopericytoma. SFTs are rare in children and adolescents, usually affecting adults aged 20-70, with no gender predilection $^{(1)}$.

SFTs are anatomically ubiquitous neoplasms, arising from the pleura, pericardium, meninges, thoracic wall, mediastinum, retroperitoneum, the deep soft tissue of the extremities or of the head and neck (particularly affecting the orbit ${ }^{2}$ ), or from the subcutaneous tissue. Other primary tumour locations reported include the salivary glands, different segments of the gastrointestinal tract, the liver, the lungs, the thyroid gland, the kidneys and the adrenals, as well as testis, spermatic cord or prostate $^{(3,4)}$.

Accounting for less than $5 \%$ of the pleural tumours, solitary fibrous tumours of the pleura (SFTP) are usually described as relatively benign neoplasms (intermediate rarely metastasising fibroblastic tumour). However, up to $10 \%-20 \%$ of the cases reported in literature display malignant features ${ }^{(5,6)}$, the pathological examination of the specimen being mandatory not only for differentiating malignant from benign disease, but also for establishing the diagnosis of SFTP, as the clinical presentation and radiological examination lack specificity. SFTPs are generally slowly growing neoplasms, and most of the patients are asymptomatic for a long time, as symptoms such as dyspnoea, cough, or chest pain appear usually as consequences of the mass effect within the thoracic cavity ${ }^{(7)}$.

Finger clubbing or hypoglycaemia are also reported, but most of the SFTPs are incidental imagistic findings, either on chest X-rays (where they appear as a peripheral opacity pertaining to the pleura, with well-defined borders) or on CT (the computed tomography provides more accurate information regarding the size of the tumour, its vascular supply or its relationships with the lung or chest wall) $^{(8)}$.

Due to the fact that malignant SFTP is an uncommon finding as aetiology of intrathoracic masses arising from the pleura, available data on this very rare neoplasm with unpredictable evolution is scarce, hence the importance of case reports or case series in understanding its clinical, radiological, histopathological and immunohistochemical characteristics, as well as the therapeutic recommendations.

We present a case of SFTP alongside a review of the typical clinical, imagistic and pathologic features consistent with this diagnosis. 

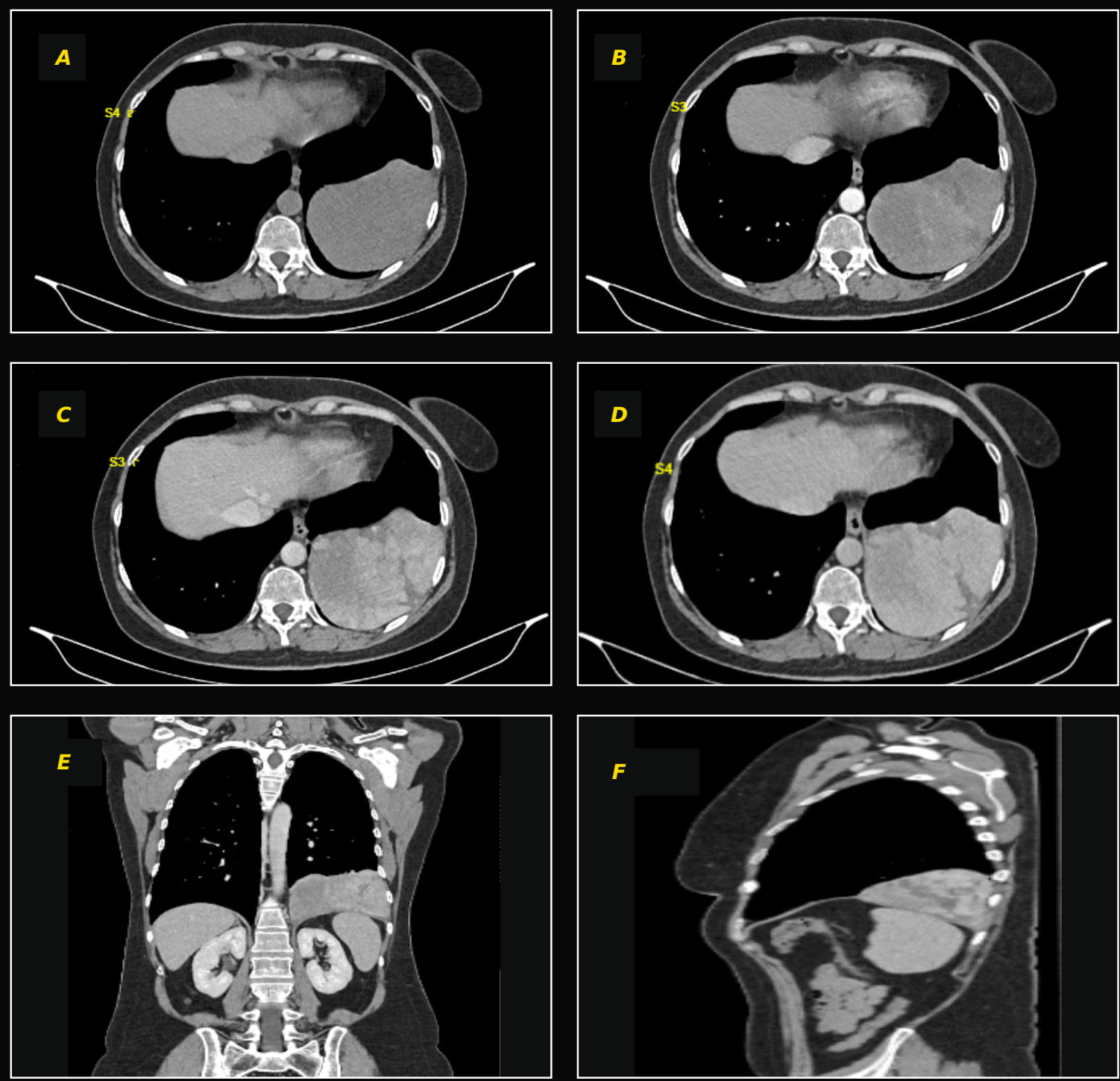

Figure 1. Preoperative thoracoabdominal CT scan. A: axial section, native, B: axial section, arterial phase, C:axial section, venous phase, D: axial section, delayed phase, E: coronal section, venous phase, E: sagital section, venous phase
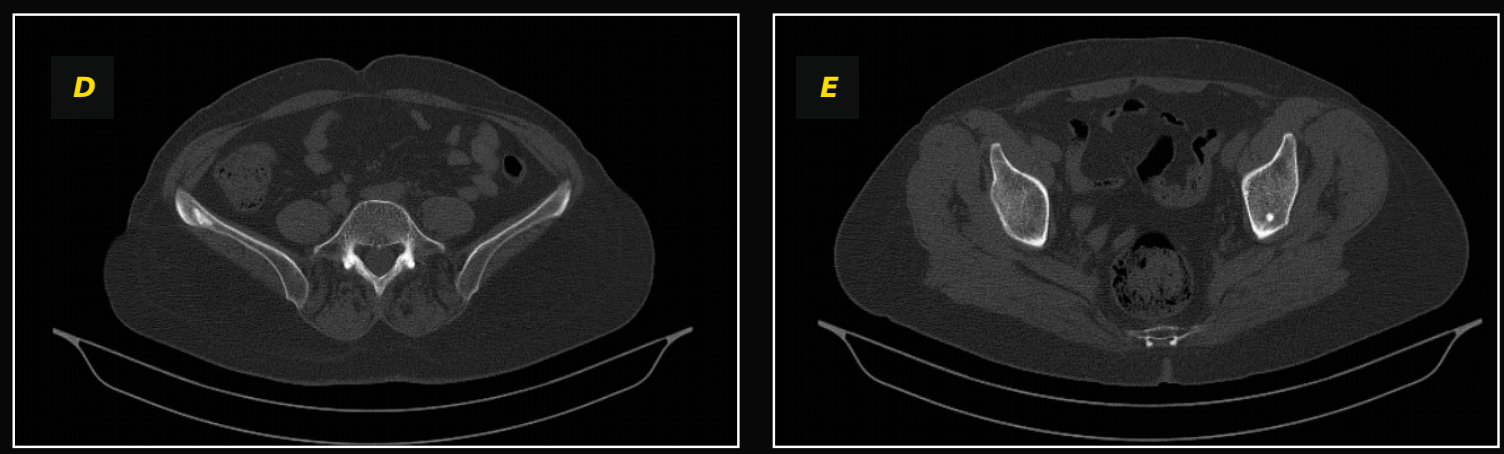

Figure 2. Postoperative control CT scan. A: axial section, native, $B$ : axial section, arterial phase, C: axial section, venous phase, D: axial section, native - right iliac wing osteocondensation, E: axial section, native left acetabular osteocondensation 


\section{INTERNAL}

\section{Clinical Cases}

\section{Case report}

A 52-year-old female, with a history of thoracic and lumbar hernias, was admitted to our clinic on February 4, 2020, complaining of lumbar pain radiating to the right inferior member. She had no history of smoking or exposure to any chemical substances like asbestos, and no previous home medication. Physical examination showed no other abnormalities except paravertebral muscle contracture, and the laboratory workup was unremarkable.

The routine chest X-ray PA view revealed a large and vaguely lobulated opacity diminishing the transparency of the base of the left lung, without air bronchogram, thus being suggestive of a proliferative process rather than an atelectatic one. The intrathoracic or intraabdominal nature of the opacity could not be established in the PA chest X-ray; therefore, a left latero-thoracic ultrasound was performed, describing a 9/6 $\mathrm{cm}$ supradiaphragmatic mass. Correlating these imagistic findings, a pleural tumour mass was suspected, requiring further investigation. The CT examination of the thorax better characterized the tumour as a well-circumscribed, homogenous pleural mass in relation to the left hemi-diaphragm and the left basal thoracic wall, measuring $80 / 120 \mathrm{~mm}$ axially and $84 \mathrm{~mm}$ craniocaudally, and presenting an inhomogeneous contrast enhancement, suggestive of a solitary fibrous tumour (Figure 1 ). The concomitant abdominal CT established the presence of a spontaneously hypodense lesion located in the caudate lobe of the liver, measuring $15 \mathrm{~cm}$, with progressive contrast enhancement and a homogeneous pattern in the late phase, the nonspecific features of the lesion requiring an MRI characterisation.

Three weeks after the admission to our clinic, at the moment of the surgical evaluation, the patient presented with dry cough and moderate dyspnoea and on February $25^{\text {th }}$ the tumour was resected and its origin from the visceral pleura was determined. The post operatory evolution was favourable, and she was discharged, establishing the further treatment pending the histopathological result.

Macroscopically, the surgical specimen consisted of an encapsulated tumoral mass measuring 10/6/8,5 cm. Microscopically, the tumoral proliferation delimitated by a fibroconnective capsule was composed of spindle cells, with round and slightly hyperchromatic nuclei, organized in hypercellular areas, with focally high mitotic index ( $>4$ mitoses/2 $\mathrm{mm}^{2}$ ), alternating with paucicellular areas, with marked fibrosis, stromal hyalinization and areas of ischemic necrosis. The intratumoral vessels presented perivascular hyalinization. The tumoral proliferation did not infiltrate the tumour capsule. Thus, this 


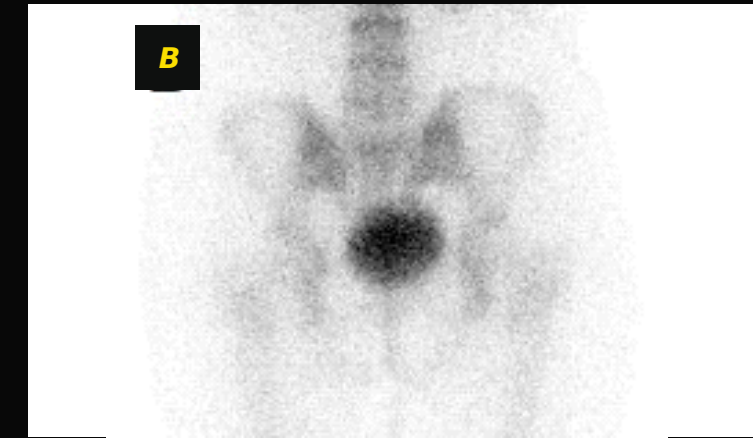

Figure 3. Bone scintigraphy. A: anterior view, B: posterior view
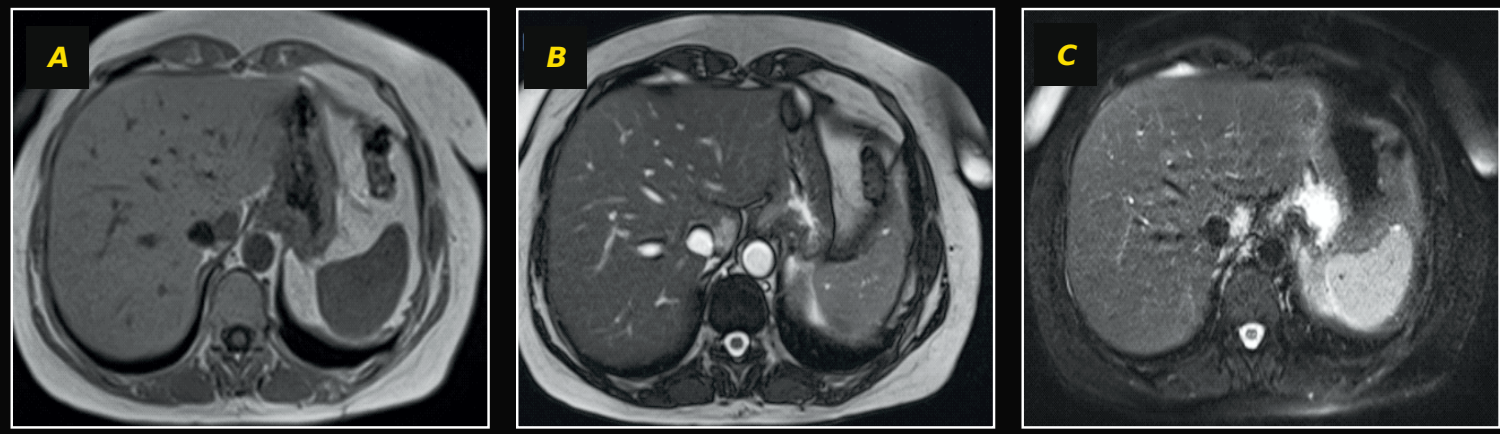

Figure 4. Abdominal MRI, axial section A: T1, B: T2, C: T2 FS

histopathological aspect was suggestive for SFTP with malignant features. The tumour cells were diffusely positive for CD34, and negative for CLA (cutaneous lymphocyte antigen). The ACT (antichymotrypsin) staining was negative in tumour cells and positive in vessels. In the hypercellular tumour areas ki67 was expressed in $7-10 \%$ of the tumour cells. The immunohistochemistry results correlated with the histopathological aspect are consistent with the diagnostic of solitary fibrous tumour of the pleura with areas of malignant transformation.

Four months after the surgery, a control CT scan revealed the post total resection of the tumoral mass status, characterised by retractile fibrotic bands and latero-basal and postero-basal pleural thickenings (aspect of pleuro-pulmonary adhesion), without any pleural effusion, pulmonary parenchyma nodules or consolidation, pathological hilar or mediastinal adenopathy, or arterial pulmonary thrombi (Figure 2).

The previously described liver nodule located in the caudate lobe was still present, measuring $15 \mathrm{~mm}$ and displaying a slow centripetal haemangioma-like contrast enhancement, without any sub-diaphragm adenopathy or free peritoneal fluid. However, the CT examination described two areas of osteocondensation: the one highlighted in the right iliac wing had a diameter of $15 / 6$ $\mathrm{mm}$, while the other lesion from the left acetabulum was small and round. Their uncertain appearance resulted in the recommendation for a bone scintigraphy, which did not describe any suspicious foci in the pelvic bones, therefore the scintigraphy aspect was not suggestive for secondary bone lesions (Figure 3). 
The MRI examination further describes the liver nodule located in the caudate lobe as T2/T2 FS- hyperintense, T1-hypointense, welldemarcated, measuring 21/19 $\mathrm{mm}$ axially and $20 \mathrm{~mm}$ craniocaudally, bilobed, relatively homogenous, with signal reduction in long TE sequence, thus having the native MRI appearance of a haemangioma. For technical reasons, contrast examination was not possible. Two other nodules, having similar characteristics, were found in segments VII (5-6 mm) and VIII (4mm) (Figure 4).

\section{Discussion}

Although Wagner was the first to report a case of a primary localized pleural tumour in $1871^{(9)}$, the first description of the SFTP features is attributed to Klemperer and Rabin $^{(10)}$ and due to the fact that they were originally thought to arise from the mesothelium of the pleura they were classified as localized mesotheliomas. The scarcity of this tumour as well as the lack of a clear nomenclature (over the years, numerous terms were used to define these tumours: localized mesothelioma, localized fibrous mesothelioma, fibrous mesothelioma, solitary fibrous mesothelioma, subserosa fibroma, pleural fibroma, submesothelial fibroma ${ }^{(11)}$ ) have led to great confusion regarding the pathological characteristics and clinical evolution and prognosis. In the last years, the extended use of immunohistochemistry staining in the pathological diagnosis of pleural tumours and the development of electron microscopy established that this neoplastic growth stems from the noncommitted mesenchymal layer underneath the pleural mesothelium ${ }^{(12,13)}$, the mesenchymal origin being supported by the lack of cytoplasmic keratin expression and the positive staining for vimentin and $\mathrm{CD} 34^{(14,15)}$. These findings led to the change of nomenclature from localized mesothelioma to SFTP $^{(16)}$.

With an estimated incidence of 2.8 cases per 100000 hospitalized patients, SFTPs can occur at any age, but they are usually diagnosed in middle-aged adults ${ }^{(7)}$, reaching a peak in the sixth and the seventh decades of life ${ }^{(17)}$. Although some authors have noticed a slight predilection for the female gender, most of the reports reveal an equal distribution between the two genders ${ }^{(17,18,19,20)}$. No etiological agent has been established until now, with no link between the tumour occurrence and exposure to environmental factors, such as tobacco or asbestos ${ }^{(21)}$, and no identified genetic predisposition (there is only one report of SFTP in family members ${ }^{(22)}$ ). SFTPs may have a wide distribution throughout the pleural cavity, but it seems that most of them arise from the visceral pleura (about two thirds of the pleural SFTPS $^{(7)}$ ), and although the tumours occurring 
in the parietal pleura tend to be larger, there is inconclusive evidence that the site of pleural origin has any impact on the prognosis $^{(8)}$.

Due to their slow growth rate, many patients are asymptomatic, approximately one third of all the cases being diagnosed based on the initial incidental finding on chest imaging ${ }^{(7)}$. When present, symptoms are variable and nonspecific: chest pain, cough, dyspnoea (a result of tumoral mass effect and compression) or general malaise with weight loss and fever ${ }^{(1,7)}$.

In rare cases obstructive pneumonitis, wheezing or haemoptysis were reported as symptoms of SFTPs ${ }^{(6,23)}$. SFTPs can be associated with paraneoplastic syndromes. One of the most frequent paraneoplastic syndrome reported is the Pierre MarieBamberger syndrome (hypertrophic pulmonary osteoarthropathy), which affects up to $20 \%$ of the patients with SFTP ${ }^{(21)}$, and it appears that the swelling and pain of the bone and joints attributed to the hyaluronic acid produced excessively by the tumour ${ }^{(8)}$ are associated with tumours with a diameter larger than $7 \mathrm{~cm}^{(24)}$. In these patients the complete physical examination frequently reveals clubbing of the fingers. Another paraneoplastic syndrome associated with SFTPs is the Doege-Potter syndrome, caused by the ectopic tumoral secretion of IGF-2 (insulin-like growth factor 2$)^{(25)}$, probably due to the loss of IGF-2 imprinting ${ }^{(26)}$. These patients present with labile and refractory hypoinsulinemic hypoglycaemia, the incidence of which appears to be higher in tumours with a higher mitotic rate $e^{(6,27,28)}$. The symptoms characteristic for the paraneoplastic syndromes attenuate and gradually disappear within weeks or months after the complete surgical resection of the tumour ${ }^{(5,7,8,29)}$.
Chest imaging plays an important role in the early evaluation of the patients with SFTPs, as in many cases the tumour is an incidental finding on a routine chest $X$-ray ${ }^{(30)}$. On a plain radiography, the tumoral mass is usually homogenous and circumscribed, although lobulated lesions have been reported ${ }^{(11)}$. The obtuse angle formed between the opaque mass and the chest wall suggest its extrapulmonary pleural location, while the size of the tumour is highly variable. The position and imagistic appearance may change over a series of chest X-rays when the position of the patient changes, provided that the tumour is pedunculated. The invasion and erosion of the ribs, pleural effusion and calcifications are not typical, but may be present.

A more accurate imagistic characterisation of the tumour is provided by the chest CT, revealing a solid mass with soft tissue attenuation on unenhanced scans, with relatively intense and homogenous background enhancement after contrast administration, due to the important vascular supply. If the tumour presents areas of necrosis, myxoid degeneration or haemorrhage the CT scan may reveal nonenhancing areas.

The relationship of the tumour with the thoracic wall is best established by the CT scan and not only is it essential for guiding the surgical approach, but also is definitory for the differential diagnosis with a parenchymal lesion $^{(31,11)}$. However, when the pleural tumour is located in an interlobar fissure, it appears to be surrounded by lung parenchyma, making it extremely challenging to differentiate from an intraparenchymal mass ${ }^{(11)}$. If pedunculated, the CT scan may in some cases highlight the pedicular attachment of the tumour. In $\mathrm{T} 1$ and T2 weighted MRI scans, the signal tends to be typically low to intermediate, due to the 


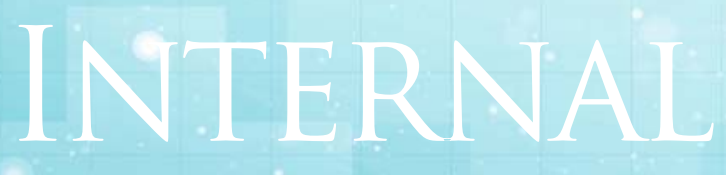

Clinical Cases.

important fibrous tumoral component, while high signal areas may suggest areas of myxoid degeneration or necrosis, which are better defined by $\mathrm{MRI}^{(32)}$.

Malignant variants of SFTPs are more often associated with larger size (more than $10 \mathrm{~cm}$; malignant SFTPs are generally larger, as genetic mutations have more time to develop $\left.{ }^{(6,29,34)}\right)$, calcifications or necrosis within the tumoral mass, lobulate and ill-defined margins or ipsilateral pleural effusion (occurring in up to $12 \%$ of the cases $^{(33)}$ ), but there are no generally accepted definite imagistic criteria to differentiate benign forms from the malignant ones of SFTPs ${ }^{(7,34)}$, thus making the histopathological examination of the specimen mandatory.

Preoperative fine needle aspiration biopsies may provide diagnostic material for immunohistochemistry, but in most of the cases they are inadequately cellular, thus making them unsuitable for diagnosis (useful in less than half of the patients ${ }^{(19)}$ ). For a comprehensive histopathologic evaluation, a complete tumoral resection is recommended. Macroscopically, as suggested by the terminology, SFTPs are generally solitary, solid grey and well-circumscribed masses, highly variable in size (although larger tumours seem to be more likely to be malignant, the size does not necessarily correlate with the malignant character of the tumour ${ }^{(8,33)}$ ) and frequently pedunculated.
Calcification, cystic transformation, haemorrhage or necrosis may be identified ${ }^{(1)}$. Histologically, SFTPs consist of monomorphic fibroblastic spindle cells, surrounded by a dense collagenous background with variable (sometimes prominent) stromal hyalinisation in a pattern less architecture, and a variable number of differently-sized branching hemangiopericytoma-like vessels, with frequent perivascular hyalinization $n^{(1,6,7)}$.

The tumour may exhibit focal areas of fascicular or storiform proliferation pattern, making the differential diagnosis with fibrosarcoma or malignant fibrous histiocytoma more challenging. Benign SFTPs are usually hypocellular, with less than 3 mitoses $/ 2 \mathrm{~mm}^{2}$, with infrequent necrosis and limited cytological atypia(1). Criteria that define malignant forms of SFTPs, according to England et al. and the WHO classification of tumours of soft tissue and bone, include hypercellularity translated as overlapping of the nuclei, high mitotic index (more than 4 mitoses/10 high-power fields), pleomorphism and nuclear atypia, tumour necrosis, and/or infiltrative margins ${ }^{(1,6)}$.

Immunohistochemistry plays an important role in distinguishing SFTPs from other pleural tumours, such as synovial sarcoma, malignant fibrous histiocytoma or sarcomatoid mesothelioma. A mesenchymal derivative, SFTPs are negative for keratin and positive for vimentin ${ }^{(36)}$. Although in many 
cases the lesions are positive for CD-34, Bcl2 and CD99, these stainings are non-specific and not particularly helpful ${ }^{(1)}$. Positive in more than $95 \%$ of the cases, the STAT6 staining is considered the most specific ${ }^{(37,38)}$, being the result of the STAT6 overexpression generated by the NAB2-STAT6 gene fusion. This mutation is considered characteristic and specific for SFTPs, and results in an intrachromosomal inversion not detectable by standard karyotyping ${ }^{(39)}$. Although SFTPs are usually negative for S100, epithelial membrane antigen (EMA), actin or desmin ${ }^{(40)}$, occasional cases may stain positive for these markers, while some lesions might be SMA (smooth muscle actin)-positive ${ }^{(1)}$.

The therapeutic management of SFTPS requires the involvement of a multidisciplinary team, consisting of specialists with experience and expertise in this pathology. Surgical treatment, radiotherapy and chemotherapy, or a combination thereof, may be necessary, but the essential element, regardless of the tumour type (benign or malignant, pedunculated or sessile), is the complete surgical resection of the tumour with confirmed intraoperatory safety margins ${ }^{(5)}$.

Occasionally lung, parietal, pericardial or diaphragm resections are required ${ }^{(41)}$, open surgery being preferred to video-assisted thoracoscopic surgery (VATS), as cases of tumour recurrence have been reported at the contact points and at the ports ${ }^{(42,43)}$. In the case of previous biopsy of the tumour, the puncture site must be removed in bloc with the final surgical specimen. Positive margins have been associated with a higher rate of local recurrence and are the main prognostic factor, surgical reintervention must be considered in such cases ${ }^{(44,45)}$.

Excision with microscopic or gross positive margins may be necessary, to spare critical neurovascular structures. In such cases, postoperative radiotherapy is required and surgical clips should be left in place ${ }^{(41)}$. Chemotherapy or radiotherapy are used as adjuvant therapy in cases of incomplete tumour resection or inoperability due to extension to adjacent structures or pleural carcinosis $^{(7)}$.

Preferred systemic therapy regimens involve the administration of Bevacizumab with or without Temolozomide, Sunitinib, Sorafenib or Pazopanib, other recommended regimens being those used for soft tissue sarcomas with non-specific histologies ${ }^{(46,47,48,49,50)}$. De Perrot et al. proposed a staging system useful for guiding the surgical approach, systemic therapy and postoperative follow-up, which divides SFTPs in four main categories. Benign pedunculated SFTPs do not require adjuvant chemotherapy, as the recurrence risk is $<2 \%$, but annual imaging is recommended.

Adjuvant chemotherapy is also not recommended for benign sessile SFTPS (recurrence risk < $8 \%$ ), but imaging should be performed twice a year in the first two years and yearly thereafter. A similar approach is recommended for malignant pedunculated SFTPS, as the recurrence risk is only slightly higher (14\%). However, adjuvant chemotherapy should be considered when facing malignant sessile SFTPs, as they pose a $63 \%$ recurrence risk ${ }^{(11)}$.

The most important prognostic factor influencing survival seems to be the complete tumoral resection ${ }^{(6,19,20,29,33,34,41)}$. However, long-term follow-up after complete resection is imperative in both benign and malignant SFTPs for monitoring recurrence, as even though several authors did not report recurrence after complete resection of benign SFT $19^{(20,23,42,51)}$, there have been isolated cases of local recurrence of benign SFTPs $^{(34)}$. Local and metastatic recurrence rates for completely resected malignant 
INTERNAL

Clinical Cases.

SFTPs widely range from $14 \%$ to $86 \%^{(19,20,34,42,51)}$, and the poor prognosis of malignant SFTPs is associated with the higher recurrence rate ${ }^{(34)}$, and with the occurrence of metastases, more frequently in the liver, peritoneum, spleen and central nervous system $^{(17)}$. Long-term survival for complete resection of benign SFTPs is far superior to that of the malignant ones, which varies from $46 \%$ to $100 \%$, as reported in different surgical series $^{(19,20,29,34,41,42)}$. Long-time survival and disease free survival is significantly worse in the presence of pleural effusion, found with a higher prevalence in malignant tumors (some authors consider the pleural fluid to be the expression of direct pleural invasion or dissemination $\left.{ }^{(6,41)}\right)$. Disease free survival rates are also lower when malignant STFPs involve the chest wall ${ }^{(41)}$.

\section{Conclusions}

Solitary fibrous tumours of the pleura are rare neoplasms, and only $10-20 \%$ present malignant features. Although imagistic investigations are useful in the incipient evaluation of SFTPs, the histopathological and immunohistochemical examinations are mandatory for establishing the diagnosis and for differentiating SFTPs from other aetiologies of pleural masses. There is limited data regarding the treatment, with complete surgical resection being the golden standard for both benign and malignant SFTPs. In order to ensure an early detection of potential recurrences, long-term imagistic follow-up is recommended, particularly in malignant SFTPS.

\section{References}

1. Fletcher CDM., Bridge JA, LeeJC Extrapleural solitary fibrous tumor. World Health Organization Classification of Tumours of Soft Tissue and Bone. Lyon, France: IARC Press; 2013; 80-82

2. Furusato E, Valenzuela IA, Fanburg-Smith JC, et al. Orbital solitary fibrous tumor: encompassing terminology for hemangiopericytoma, giant cell angiofibroma, and fibrous histiocytoma of the orbit: reappraisal of 41 cases. Hum Pathol. 2011;42(1):120128.

3. Mentzel, T., Bainbridge, T. \& Katenkamp, D. Solitary fibrous tumour: clinicopathological, immunohistochemical and ultrastructural analysis of 12 cases arising in soft tissues, nasal cavity and nasopharynx, urinary bladder and prostate. Virchows Archiv 430, 445-453 (1997)

4. Nielsen GP, O'Connell JX, Dickersin GR, Rosenberg $A E$. Solitary fibrous tumor of soft tissue: a report of 15 cases, including 5 malignant examples with light microscopic, immunohistochemical, and ultrastructural data. Mod Pathol. 1997;10(10):1028-1037.

5. Robinson LA. Solitary fibrous tumors of the pleura. Cancer Control 2006; 13:264-269

6. England DM, Hochholzer L, McCarthy MJ. Localized benign and malignant fibrous tumours of the pleura. $A$ clinicopathologic review of 223 cases. Am J Surg Pathol 1989; 13:640-658.

7. Bukamur $H$, Karem E, Fares $S$, et al. A series of two cases of rare tumors: solitary fibrous tumor of the pleura. Respir Med Case Rep. 2019; 28:100872

8. Marak C.P., Dorokhova O., Guddati A.K. Solitary fibrous tumor of the pleura. Med Oncol 2013; 30:573

9. E. Wagner, Das Tuberkelähnliche Lymphadenom:(Der Cytogene Oder Reticulirte 
Tuberkel.) Von E. Wagner Mit Zwei Tafeln, Otto Wigand, (1871)

10. Klemperer $P$, Rabin LB. Primary neoplasms of the pleura: a report of five cases. Arch Pathol 1931; 11:385-412.

11. de Perrot $M$, Fischer $S$, Bru"ndler MA, Sekine $Y$, Keshavjee S. Solitary fibrous tumors of the pleura. Ann Thorac Surg. 2002; 74:285-93.

12. Al-Azzi M, Thurlow NP, Corrin B. Pleural mesothelioma of connective tissue type, localized fibrous tumor of the pleura, and reactive submesothelial hyperplasia: an immunohistochemical comparison. J Pathol 1989; 158:41-44.

13. Hernandez FJ, Hernandez BB. Localized fibrous tumors of the pleura: a light and electron microscopic study. Cancer 1974; 34:1667-1674.

14. Flint $A$, Weiss SW. CD-34 and keratin expression distinguishes solitary fibrous tumor (fibrous mesothelioma) of pleura from desmoplastic mesothelioma. Hum Pathol. 1995;26(4):428-31.

15. van de Rijn $M$, Lombard CM, Rouse RV. Expression of CD34 by solitary fibrous tumors of the pleura, mediastinum, and lung. Am J Surg Pathol. 1994;18(8):814-20.

16. Chan JK. Solitary fibrous tumour-everywhere, and a diagnosis in vogue. Histopathology. 1997;31(6):568-76. 17. Okike N, Bernatz PE, Woolner LB. Localized mesothelioma of the pleura: benign and malignant variants. J Thorac Cardiovasc Surg. 1978;75(3):363-72. 18. Mitchell JD. Solitary fibrous tumor of the pleura. Semin Thorac Cardiovasc Surg. 2003;15(3):305-9.

19. Magdeleinat $P$, Alifano $M$, Petino $A$, Le Rochais JP, Dulmet $E$, Galateau F, Icard $P$, Regnard JF. Solitary fibrous tumors of the pleura: clinical characteristics, surgical treatment and outcome. Eur J Cardiothorac Surg. 2002;21(6):1087-93.

20. Sung SH, Chang JW, Kim J, Lee KS, Han J, Park SI. Solitary fibrous tumors of the pleura: surgical outcome and clinical course. Ann Thorac Surg. 2005;79(1):303-7. 21. Rosado-de-Christenson ML, Abbott GF, McAdams HP et al: From the Archives of the AFIP: Localized Fibrous Tumors of the Pleura. Radiographics, 2003; 23: 759-83

22. Jha V, Gil J, Teirstein AS. Familial solitary fibrous tumor of the pleura: a case report. Chest. 2005;127(5):1852-4.

23. de Perrot $M$, Kurt AM, Robert JH, Borisch $B$, Spiliopoulos A. Clinical behavior of solitary fibrous tumors of the pleura. Ann Thorac Surg. 1999;67(5):1456-9

24. M. Briselli, E.J. Mark, G.R. Dickersin, Solitary fibrous tumors of the pleura: eight new cases and review of 360 cases in the literature, Cancer 47 (1981) 2678-2689

25. N.A. Campbell, P.N. Antippa, Solitary fibrous tumour of the pleura, Heart Lung Circ. 15 (2006) 400-401
26. Hajdu M, Singer S, Maki RG, et al. IGF2 overexpression in solitary fibrous tumours is independent of anatomical location and is related to loss of imprinting. J Pathol 2010; 221: 300-307

27. Balduyck B, Lauwers P, Govaert K, Hendriks J, De Maeseneer $M$, Van Schil P. Solitary fibrous tumor of the pleura with associated hypoglycemia: Doege-Potter syndrome: a case report. J Thorac Oncol. 2006;1(6): 588-90.

28. Zafar H, Takimoto CH, Weiss G. Doege-Potter syndrome: hypoglycemia associated with malignant solitary fibrous tumor. Med Oncol. 2003;20(4):403-8.

29. Rena O, Filosso PL, Papalia E, Molinatti M, Di Marzio P, Maggi $G$, Oliaro A. Solitary fibrous tumour of the pleura: surgical treatment. Eur J Cardiothorac Surg. 2001;19(2):185-9.

30. Lee KS, Im JG, Choe KO et-al. CT findings in benign fibrous mesothelioma of the pleura: pathologic correlation in nine patients. AJR Am J Roentgenol. 1992;158 (5): $983-6$

31. Cardinale L, Ardissone F, Garetto I, Marci V, Volpicelli $G$, Solitro F, Fava C. Imaging of benign solitary fibrous tumor of the pleura: a pictorial essay. Rare Tumors. 2010;2(1)

32. Harris GN, Rozenshtein A, Schiff MJ. Benign fibrous mesothelioma of the pleura: MR imaging findings. AJR AmJ Roentgenol. 1995;165 (5): 1143-4

33. Cardillo G, Carbone L, Carleo F, Masala N, Graziano P, Bray A, Martelli M. Solitary fibrous tumors of the pleura: an analysis of 110 patients treated in a single institution. Ann Thorac Surg. 2009;88(5):1632-7.

34. K.M. Harrison-Phipps, F.C. Nichols, C.D. Schleck, C. Deschamps, S.D. Cassivi, P.H. Schipper, M.S. Allen, D.A. Wigle, P.C. Pairolero, Solitary fibrous tumors of the pleura: results of surgical treatment and long-term prognosis, J. Thorac. Cardiovasc. Surg. 138 (2009) 19-25.

35. L.F. Tapias, M. Mino-Kenudson, H. Lee, C. Wright, H.A. Gaissert, J.C. Wain, D.J. Mathisen, M. Lanuti, Risk factor analysis for the recurrence of resected solitary fibrous tumours of the pleura: a 33-year experience and proposal for a scoring system, Eur. J. Cardiothorac. Surg. 44 (2012) 111-117.

36. Supakul R, Sodhi A, Tamashiro CY, Azmi SS, Kadaria D. Solitary Fibrous Tumor of the Pleura: A Rare Cause of Pleural Mass. Am J Case Rep. 2015 Dec 3;16:854-7.

37. Doyle $L A$, Vivero $M$, Fletcher $C D$, et al. Nuclear expression of STAT6 distinguishes solitary fibrous tumor from histologic mimics. Mod Pathol. 2014; 27:390-5

38. Yoshida A, Tsuta K, Ohno $M$, et al. STAT6 immunohistochemistry is helpful in the diagnosis of solitary fibrous tumors. Am J Surg Pathol 2014; 38:552-9 39. Robinson DR, Wu YM, Kalyana-Sundaram $S$, et al. Identification of recurrent NAB2-STAT6 gene fusions in 
Clinical Cases.

solitary fibrous tumor by integrative sequencing. Nat Genet. 2013; 45:180-5

40. M. Kohler, C.F. Clarenbach, P. Kestenholz, M. Kurrer, H.C. Steinert, E.W. Russi, W. Weder, Diagnosis, treatment and long-term outcome of solitary fibrous tumours of the pleura, Eur. J. Cardiothorac. Surg. 32 (2007) 403-408.

41. Lococo, F, Cesario, A, Cardillo, G. Malignant solitary fibrous tumors of the pleura: retrospective review of a multicenter series. J Thorac Oncol. 2012;7: 1700-1701

42. Cardillo G, Facciolo F, Cavazzana AO, Capece G, Gasparri R, Martelli M. Localized (solitary) fibrous tumors of the pleura: an analysis of 55 patients. Ann Thorac Surg. 2000;70(6):1808-12.

43. Nomori H, Horio H, Fuyuno G, Morinaga S. Contacting metastasis of a fibrous tumor of the pleura. Eur J Cardiothorac Surg. 1997;12(6):928-30

44. Zagars GK, Ballo MT, Pisters PWT, Pollock RE, Patel $S R$, Benjamin RS. The surgical margin and reresection in the management of soft tissue sarcoma with conservative surgery and radiation therapy. Cancer. 2003; 97: 2544- 2553.

45. O'Donnell PW, Griffin AM, Eward WC, et al. The effect of the setting of a positive surgical margin in soft tissue sarcoma. Cancer. 2014;120(18):2866-2875.

46. Park MS, Patel SR, Ludwig JA, et al. Activity of temolozomide and bevacizumab in the treatment of locally advanced, recurrent, and metastatic hemangiopericytoma and malignant solitary fibrous tumor. Cancer 2011; 117:4939-4947

47. George S, Merriam P, Maki RG, et al. Multicenter phase II of sunitinib in the treatment of nongastrointestinal stromal tumor sarcomas. J Clin Oncol 2009; 27:3154-3160 48. Stacchioti $S$, Negri T, Libertini $M$, et al. Sunitinib maleate in solitary fibrous tumor (SFT). Ann Oncol 2012; 23:3171-3179

49. Valentin T, Fournier $C$, Penel $N$, et al. Sorafenib in patients with progressive malignant solitary tumors: a subgrup analysis from a phase II study of the French Sarcoma Group (GSF/GETO). Invest New Drugs 2013;31(6): 1626-1627

50. Ebata T, Shimoi T, Bun S, et al. Efficacy and safety of pazopanib for recurrent of metastatic solitary fibrous tumor. Oncology 2018; 94:340-344.

51. Santos RS, Haddad R, Lima CE, Liu YL, Misztal M, Ferreira TD, et al. Patterns of recurrence and long-term survival after curative resection of localized fibrous tumors of the pleura. Clin Lung Cancer. 2005; 7:197-201 